\title{
EDUCAÇÃO AMBIENTAL NO ENSINO NÃO-FORMAL: ESTUDO DE CASO DO PROJETO HARMONIA CONSCIENTE
}

\author{
Aline Paez Silveira ${ }^{1}$ \\ Cristiano Sordi Schiavi ${ }^{2}$
}

Resumo: O objetivo desta pesquisa é analisar o "Projeto Harmonia Consciente", no ano de 2018, que se constitui numa atividade de Educação Ambiental de caráter não-formal, com foco na temática dos resíduos sólidos, sendo desenvolvido no evento cultural "Acampamento Farroupilha", no Município de Porto Alegre, capital do Estado do Rio Grande do Sul, Brasil. O estudo de caso demonstrou como uma ação educativa pode ser conduzida em espaços nãoformais e revelou sobre a importância dessa prática para a criação de espaços de diálogo, que possam informar, sensibilizar e mobilizar a sociedade sobre a temática dos resíduos sólidos, de acordo com as quatro linhas de atuação da Política Nacional de Educação Ambiental.

Palavras-chave: Educação Ambiental; Ensino Não-Formal; Desenvolvimento Sustentável.

Abstract: The objective of this research is to analyze the "Projeto Harmonia Consciente", in 2018, which is a non-formal environmental education activity, focusing on the theme of solid waste, being developed in the cultural event "Acampamento Farroupilha", in the municipality of Porto Alegre, capital of the State of Rio Grande do Sul, Brazil. The case study demonstrated how an educational action can be conducted in non-formal spaces and revealed the importance of this practice for the creation of spaces for dialogue, which can inform, sensitize and mobilize society on the theme of solid waste, in accordance with the four lines of action of the National Environmental Education Policy.

Keywords: Environmental Education; Non-Formal Education; Sustainable Development.

\footnotetext{
${ }^{1}$ Consórcio Público de Saneamento Básico da Bacia Hidrográfica do Rio dos Sinos.

E-mail: aline@paez.com.br, Link para o Lattes: http://lattes.cnpq.br/4498982303010704

2 Universidade Federal do Rio Grande do Sul. E-mail: cristianosordi@hotmail.com,

Link para o Lattes: http://lattes.cnpq.br/5749597465270521
}

Revbea, São Paulo, v.16, № 1: 305-325, 2021.

revista brasileira 


\section{Introdução}

O Brasil, como um dos países comprometidos em atender a Agenda 2030 da Organização das Nações Unidas - ONU, demonstrou, numa análise recente sobre os avanços do país em relação aos 17 Objetivos de Desenvolvimento Sustentável - ODS, estar distante do cenário ideal quanto à geração e à gestão de resíduos sólidos, possuindo um padrão de consumo de bens e serviços insustentável (GTSC A2030, 2018). Segundo os dados da análise, estima-se que, por dia, gera-se cerca de 160 mil toneladas de resíduos sólidos, sendo que destes apenas $40 \%$ são passíveis de reaproveitamento e reciclagem, e que há poucos avanços sobre o cumprimento da Política Nacional de Resíduos Sólidos - PNRS, no que tange às responsabilidades dos produtores sobre o ciclo de vida de seus produtos (GTSC A2030, 2018).

Além disso, de acordo com o Instituto de Pesquisa Econômica Aplicada - IPEA, apenas $13 \%$ dos resíduos sólidos urbanos foram reciclados no ano de 2017 (GTSC A2030, 2018), evidenciando a necessidade de reestruturação das atuais práticas de gestão de resíduos e da implementação de políticas e programas de cunho ambiental e educativo, a fim de "assegurar padrões de produção e consumo sustentáveis", tal como determina o ODS de número 12 da Agenda 2030. A discussão da temática da gestão de resíduos, da sustentabilidade e da responsabilidade compartilhada através da prática de Educação Ambiental mostra-se essencial, uma vez que ela pode propiciar uma maior participação da sociedade, tornando-a protagonista do gerenciamento dos resíduos sólidos.

Desse modo, cabem as diversas organizações civis e instituições públicas e privadas a cooperação na busca por uma educação voltada para o estudo das questões ambientais, por meio de ações e práticas educativas de caráter permanente, que estejam presentes tanto na educação formal, em escolas e instituições de ensino, como nas atividades de educação não-formal, em ambientes fora da escola, para que a temática ambiental atinja os mais variados espaços - sejam dentro de empresas e entidades, em atividades ao ar livre, museus, eventos culturais, entre outros. A escola não é o único ambiente que auxilia no processo de formação, pois a educação é um processo constante que também ocorre no ambiente familiar e cultural onde o aluno se encontra (QUADRA; D'ÁVILA, 2016).

Nesse contexto, o presente artigo tem por objetivo analisar as práticas educacionais do Projeto Harmonia Consciente, em 2018, que se configura como uma ação de Educação Ambiental no ensino não-formal, de atuação no evento cultural "Acampamento Farroupilha", no Município de Porto Alegre/RS, tendo como base as linhas de atuação da Política Nacional de Educação Ambiental (PNEA). A prática educativa em ambientes não-formais é de grande relevância, pois permite o desenvolvimento de uma educação continuada e o acesso à informação para diferentes públicos, de modo a fomentar discussões sobre as problemáticas atuais, a exemplo da temática dos resíduos sólidos, foco de atuação das ações educativas do Projeto. Para tanto, foram levantadas informações a respeito da importância da Educação Ambiental não-formal Revbea, São Paulo, v.16, № 1: 305-325, 2021. 
como uma ferramenta de transformação social e sustentabilidade, e se propôs discutir sobre os saberes necessários à prática educativa, por se tratarem de conceitos norteadores das atividades de Educação Ambiental.

\section{Revisão de Literatura}

\section{Educação Ambiental no ensino não-formal}

Tendo em vista a constante degradação ambiental e os problemas sociais da atualidade, urge a necessidade de fortalecer a importância de garantir padrões ambientais adequados e estimular uma crescente consciência ambiental, de modo a enfrentar essas problemáticas de forma concomitante (JACOBI, 2003). Nesse caso, a Educação Ambiental se apresenta como uma função transformadora, pois ela está ligada a uma nova forma de relação ser humano/natureza, centrada no exercício da cidadania e na reformulação de valores éticos e morais, individuais e coletivos, representando a possibilidade de motivar e sensibilizar as pessoas, numa perspectiva orientada para 0 desenvolvimento sustentável (JACOBI, 2003).

Da mesma forma, o Programa Nacional de Educação Ambiental ProNEA (2014, p.105), afirma que "é cada vez mais reconhecida a relevância da Educação Ambiental em favor de uma sociedade mais justa e sustentável, por se constituir num dos meios de enfrentamento à degradação socioambiental, em escala local, nacional e global”. A Lei $n^{\circ} 9.795$, de abril de 1999, que institui a Política Nacional de Educação Ambiental - PNEA, define em seu Art. 10, a Educação Ambiental como (BRASIL, 1999) "os processos por meio dos quais o indivíduo e a coletividade constroem valores sociais, conhecimentos, habilidades, atitudes e competências voltadas para a conservação do meio ambiente, bem de uso comum do povo, essencial à sadia qualidade de vida e sua sustentabilidade".

De acordo com a PNEA, a Educação Ambiental deve ser exercida em caráter formal e não-formal, sendo a educação formal "desenvolvida no âmbito dos currículos das instituições de ensino públicas e privadas da educação escolar - Art. 9" e a educação não-formal por intermédio de "ações e práticas educativas voltadas à sensibilização da coletividade sobre as questões ambientais e à sua organização e participação na defesa da qualidade do meio ambiente - Art.13", de maneira que seja "um componente essencial e permanente da educação nacional" (BRASIL, 1999). As linhas de atuação da Educação Ambiental, tanto no ensino formal como no ensino não-formal, segundo a PNEA, devem ser desenvolvidas por meio da: I - capacitação de recursos humanos; II - desenvolvimento de estudos, pesquisas e experimentações; III - produção e divulgação de material educativo; e IV acompanhamento e avaliação; de modo que essas linhas estejam interrelacionadas (BRASIL, 1999).

Para Gohn (2006), a educação de caráter não-formal pode ser vista como uma complementação da educação escolar, sem vir a substituir ou 
competir com a educação formal, visto que é uma educação que se aprende via os processos de compartilhamento de experiências, principalmente em espaços e ações coletivas cotidianas, localizada fora das escolas, em locais informais. Do mesmo modo, a Lei de Diretrizes e Bases da Educação Nacional - LDB estabelece, no Art. $1^{\circ}$, que "a educação abrange os processos formativos que se desenvolvem na vida familiar, na convivência humana, no trabalho, nas instituições de ensino e pesquisa, nos movimentos sociais e organizações da sociedade civil e nas manifestações culturais" (BRASIL, 1996), demonstrando a amplitude da prática educativa e das suas formas de atuação.

Quadra e D'Ávila (2016) também ressaltam que a educação não-formal não precisa seguir vários requisitos formais, já que ela pode ser realizada em qualquer ambiente, além de possibilitar uma maior liberdade para ensinar e aprender, facilitando o atendimento das necessidades de cada pessoa. $\mathrm{Na}$ percepção de Gohn (2006), a educação não-formal ocorre em ambientes e situações interativas construídas coletivamente, na qual a participação dos indivíduos é, comumente, optativa. Assim, percebe-se que a Educação Ambiental não-formal possibilita a criação de espaços de diálogo, mas cabe ao educador promover a participação dos indivíduos com o uso de ferramentas didáticas atrativas, de maneira a impactar as pessoas e influenciar suas tomadas de decisões e a escolha por formas de produção e consumo de bens e serviços mais sustentáveis.

\section{Saberes necessários à prática de Educação Ambiental}

É sabido que o ser humano pertence ao denominado "mundo-natureza" como uma unidade interdependente, assim destacado por Dickmann e Carneiro (2012). Entretanto, é fundamental que em toda e qualquer prática de Educação Ambiental essa visão se faça presente, de modo que a educação, segundo os autores (2012, p. 92), possibilite "[...] a construção de um sentimento de pertencimento ao mundo e uma compreensão de mundo sistêmico-dinâmica". Para Dickmann e Carneiro (2012), a ideia de pertencimento implica no desenvolvimento de uma consciência ecológica, capaz de possibilitar a reflexão sobre as nossas ações. Da mesma forma, Freire (1996, p. 85) destaca que a mudança é possível e que o "[...] papel no mundo não é só o de quem constata o que ocorre mas também o de quem intervém como sujeito de ocorrências", sendo a educação uma forma de intervenção no mundo, um aprender para "transformar a realidade, para nela intervir, recriando-a" (FREIRE, 1996, p. 76).

Uma vez estabelecida essa noção de pertencimento e a possibilidade de intervenção, cabe destacar o papel do educador no ensino e aprendizagem que, de acordo com Freire (1996), diz respeito à criação de possibilidades para a produção ou a construção de conhecimentos do educando. Nessa perspectiva, deve haver uma relação dialógica entre educador e aluno, onde ambos precisam ser protagonistas do processo educativo, ao passo que os conceitos sejam trabalhados por meio de métodos, técnicas e materiais 
diversos, aliando teoria e prática, pois, para Freire (1996), não basta o conhecimento ser apreendido pelo educando, ele precisa ser constantemente testemunhado e vivido.

Dessa forma, percebe-se que a Educação Ambiental no ensino nãoformal, tal como no ensino formal, requer um educador com conhecimento da prática pedagógica, capacitado na área ambiental e munido de informações e instrumentos para criar condições para a aprendizagem de seus educandos. Conforme Freire (1996, p. 26), "ensinar inexiste sem aprender", sendo fundamental que o educador do ensino não-formal esteja devidamente capacitado para realizar qualquer prática educativa.

Cabe também discutir sobre os objetivos da Educação Ambiental, construídos em 1977, a partir da Conferência Intergovernamental de Tbilisi, e que até hoje servem como norteadores dessa prática educativa, estando categorizados em cinco objetivos (UNESCO, 1997, p.103):

Categorias dos objetivos da Educação Ambiental:

Consciência: Ajudar grupos sociais e indivíduos a adquirirem uma consciência do meio ambiente global, sensibilizando-os para essas questões;

Conhecimentos: Ajudar grupos sociais e indivíduos a adquirirem experiências diversas e uma compreensão fundamental do meio e problemas afins;

Comportamento: Ajudar grupos sociais e indivíduos a se comportarem de acordo com uma série de valores e a criarem interesse e preocupação em relação ao meio ambiente, motivando-os de tal maneira que venham a participar ativamente da sua melhoria e proteção;

Aptidões: Ajudar grupos sociais e indivíduos a adquirirem as aptidões necessárias para determinar e resolver os problemas ambientais;

Participação: Proporcionar aos grupos sociais e indivíduos a possibilidade de participarem ativamente de tarefas voltadas para a solução dos problemas ambientais.

Os objetivos estabelecidos na Conferência, ora apresentados, podem ser uma ferramenta para orientar o educador nas suas práticas educativas, na medida em que o despertar para o engajamento e o compromisso com as questões ambientais iniciam pela tomada de consciência do educando, dada pela conscientização, que visa o esclarecimento de algo e é caracterizada por Dickmann e Carneiro (2012, p. 94) como "[...] uma busca dinâmica de conhecer criticamente a realidade para transformá-la". E esse ato de trazer algo a consciência vem acompanhado da prática de sensibilização, do exercício de sensibilidade pelo meio ambiente.

Todavia, nas diretrizes da Conferência destaca-se que "é indispensável uma Educação Ambiental que não somente sensibilize, mas também modifique 
as atitudes e proporcione novos conhecimentos [...]" (UNESCO, 1997, p. 23). Assim, observa-se a importância do conhecimento, do acesso à informação e das condições para que os conceitos sejam compreendidos e apreendidos pelos educandos e que, uma vez assimilados e acomodados, sejam colocados em prática, através das mudanças de comportamento.

As mudanças de atitude e comportamento estão relacionadas com os valores e os princípios éticos, que também devem fazer parte das ações de Educação Ambiental. De acordo com Freire (1996), o exercício educativo, como caráter formador, pressupõe 0 ensino dos conteúdos alinhado à formação moral do educando. Para tanto, torna-se essencial englobar também os conceitos de cidadania e responsabilidade socioambiental na prática educativa.

Dentre os objetivos, observa-se ainda a preocupação com o desenvolvimento de aptidões, requisitos necessários e disposição para conhecer e enfrentar as problemáticas ambientais e, para isso, é preciso estar atento não só ao contexto do local do objeto de estudo mas também a realidade $e$ as características em que o público-alvo está inserido. $\mathrm{Na}$ educação, as questões-problema devem ser refletidas em conexão com as circunstâncias histórico-culturais (DICKMANN; CARNEIRO, 2012).

Além disso, o educador deve compreender que 0 ato de ensinar envolve o saber ouvir o outro, numa escuta ativa, a fim de aprender a conversar com quem se fala, como descreve Freire (1996, p.128), "o educador que escuta aprende a difícil lição de transformar o seu discurso, às vezes necessário, ao aluno, em uma fala com ele". Assim, percebe-se que o contexto histórico-cultural a que determinada prática educativa está inserida exige do educador uma disponibilidade para o diálogo com o público-alvo, de modo empático, e o adequado conhecimento do ambiente de trabalho.

Igualmente importante tem-se a discussão da participação, da criação de meios para promover a participação da sociedade nas questões ambientais. Muitos programas e projetos referentes à temática dos resíduos sólidos, por exemplo, acabam não tendo êxito em virtude da falta de participação de uma comunidade que está pouco sensibilizada e é convocada a descartar seus resíduos sem compreender a lógica do sistema de coleta seletiva (IPEA, 2012). Nesse sentido, a atividade de Educação Ambiental em ambientes não-formais pode ser uma forma de proporcionar essa participação da comunidade, uma vez que o educador, em qualquer atividade, local ou evento, concebe a oportunidade de sensibilizar, informar e mobilizar determinado público, envolvendo-o na temática ambiental e promovendo a sua co-responsabilização.

\section{Metodologia}

Para alcançar o objetivo proposto no trabalho, foi realizada uma pesquisa qualitativa, através da análise do estudo de caso do Projeto Harmonia Consciente 2018. Para Gil (2008, p.58), o estudo de caso é uma modalidade de 
pesquisa que busca o conhecimento amplo e detalhado de um objeto de estudo, podendo ter o propósito de "descrever a situação do contexto em que está sendo feita determinada investigação", sendo assim definido como estudo de caso do tipo descritivo.

O Projeto Harmonia é caracterizado por uma ação de Educação Ambiental do ensino não-formal, de iniciativa da Associação Brasileira de Engenharia Sanitária e Ambiental - Seção RS (ABES/RS), e com atuação no evento cultural do "Acampamento Farroupilha" de Porto Alegre/RS desde o ano de 2010, totalizando nove edições em 2018. O evento faz referência à cultura e as tradições gaúchas e celebra os Festejos Farroupilhas, sendo considerado pela Administração Pública Municipal, desde 2017, uma atividade privada de responsabilidade do Movimento Tradicionalista Gaúcho - MTG, tendo entrada gratuita e aberta ao público. O Acampamento Farroupilha ocorre no Parque Maurício Sirotsky Sobrinho, também conhecido como Parque da Harmonia, no período oficial de 7 a 20 de setembro, mas o Projeto inicia suas atividades no dia $1^{\circ}$ de setembro.

Nessa pesquisa, foram apresentadas e discutidas somente as informações sobre a edição 2018 do Projeto e as suas etapas de planejamento, execução, acompanhamento e avaliação da prática educativa. As ações educativas promovidas pelo Projeto têm como foco a abordagem aos acampados dos piquetes (construção de madeira feita pelos acampados que serve de casa durante os 20 dias de Acampamento), mas o Projeto também contempla outras áreas do evento, a partir de atividades pontuais com os comerciantes da Praça de Alimentação e da Área do Artesanato, e atividades na Área de convivência, junto à praça das churrasqueiras, englobando colaboradores e visitantes do evento. Na pesquisa foram discutidas somente as experiências da prática educativa com os acampados, distribuídos em 363 piquetes.

As informações do estudo de caso foram obtidas a partir de diferentes modalidades de observação, definida por Lakatos e Marconi (2010) como as observações dos tipos sistemática, participante e individual. De acordo com as autoras (2010, p.176), a observação sistemática se refere a uma análise estruturada e planejada, que utiliza alguns instrumentos para a coleta de dados, tal como as anotações, e "realiza-se em condições controladas, para responder a propósitos pré-estabelecidos", isto é, o pesquisador sabe o que procura na investigação. Essa técnica foi realizada durante toda a fase de planejamento e desenvolvimento das ações educativas do Projeto, de fevereiro a outubro de 2018, com vistas a acompanhar os recursos necessários para viabilizar a capacitação da equipe de Educação Ambiental e os materiais educativos, de controle, apoio e avaliação das atividades.

Já as observações do tipo participante e individual foram realizadas, de modo mais intenso, durante o período de execução do Projeto, do dia $1^{\circ}$ ao dia 18 de setembro de 2018, no evento do "Acampamento Farroupilha", através do acompanhamento da equipe de trabalho e pela atuação da pesquisadora nas 
ações educativas. Segundo Lakatos e Marconi (2010), a observação participante consiste na participação real do pesquisador, de modo que ele se incorpore ao grupo de trabalho, próximo dos membros que estão sendo estudados e participando normalmente das atividades do grupo. Yin (2001) descreve que nesse tipo de observação o pesquisador não é apenas um observador passivo, ele pode participar dos eventos estudados e assumir uma variedade de funções dentro do estudo de caso, como trabalhar como membro de equipe em uma organização. Nesse caso, a pesquisadora atuou como representante da $A B E S / R S$ e ao lado da criadora do Projeto, responsável pelas ações educativas no Acampamento.

Além da observação participante, houve a observação individual, realizada pela presença constante da pesquisadora no local de estudo, acompanhando o trabalho desenvolvido pela equipe de forma periférica e a frente do público-alvo, sendo ele o observado, em visitas de campo, para fins de controle e avaliação das ações do Projeto. Na observação individual a personalidade do pesquisador é projetada sobre o observado e algumas interferências podem vir a ocorrer, mas o controle das ações é limitado (LAKATOS; MARCONI, 2010). Yin (2001) utiliza o termo "observação direta", na qual a coleta de dados é feita por meio da observação de alguns comportamentos ou condições ambientais relevantes que não se podem manipular, a exemplo da observação em visitas de campo, reuniões, atividades de passeio, análise das condições físicas de espaços de trabalho, entre outras atividades.

A discussão do estudo de caso foi elaborada mediante uma análise das ações desempenhadas no Projeto e a relação da prática de Educação Ambiental com os pressupostos estabelecidos na PNEA, por meio de suas quatro linhas de atuação (I - capacitação de recursos humanos; II desenvolvimento de estudos, pesquisas e experimentações; III - produção e divulgação de material educativo; e IV - acompanhamento e avaliação), além das contribuições de autores mencionados na revisão bibliográfica, no que diz respeito à Educação Ambiental não-formal e aos saberes necessários para a realização de uma prática educativa transformadora.

\section{Resultados e discussões}

\section{Capacitação de recursos humanos}

A capacitação de recursos humanos é essencial para a prática de Educação Ambiental do ensino não-formal, pois ela envolve todo um preparo do educador para atuar em diferentes contextos e ambientes de trabalho, aliando o conhecimento técnico da área ambiental com o processo educativo junto ao público-alvo. Segundo a PNEA, a capacitação diz respeito à incorporação da dimensão ambiental na formação, especialização e atualização de educadores de todos os níveis e modalidades de ensino e de profissionais na área de meio ambiente ou de outras áreas (BRASIL, 1999). Sendo assim, uma das ações do Projeto Harmonia Consciente 2018 foi 
selecionar pessoas com formação na área ambiental ou áreas afins, que tivessem reconhecida experiência em atividades de Educação Ambiental e participassem de um encontro de capacitação para atuar no Projeto.

As ações educativas promovidas pelo Projeto, desde a primeira edição, sempre tiveram o apoio de Universidades e Escolas de Ensino Técnico da região, por meio da participação de estudantes e recém formados, atuando como agentes de Educação Ambiental. O envolvimento de estudantes no Projeto tem o propósito de oportunizar trocas de saberes e experiências de campo com alunos já familiarizados com a temática ambiental e que possuem em sua grade curricular a disciplina de Educação Ambiental. Entretanto, a participação no Projeto não é exclusiva a estudantes, podendo também ser realizada por qualquer profissional formado na área, desde que tenha disponibilidade de horário e participe do treinamento da equipe.

A divulgação das vagas para atuar no Projeto foi realizada por meio digital, através do envio de e-mails para cursos técnicos e superiores e da postagem do edital do Projeto nas mídias sociais. O participante interessado teve que preencher um formulário de cadastro e seleção, que continha informações sobre as ações educativas que seriam desenvolvidas e solicitava dados sobre a experiência do participante em ações de Educação Ambiental, se já havia participado de alguma edição do Projeto, entre outras questões. Como resultado, 14 interessados preencheram o formulário e todos atenderam os critérios pré-estabelecidos pela Coordenação do Projeto.

Os participantes selecionados foram, então, convocados a comparecer em dois encontros. O primeiro encontro foi uma reunião de alinhamento do Projeto, realizada no dia 01/08, e o segundo um treinamento sobre a prática de Educação Ambiental, realizado no dia 22/08, sendo a presença obrigatória para a atuação dos participantes nas atividades do Acampamento. Os dois encontros foram conduzidos pela pesquisadora e a criadora do Projeto, que coordenaram a equipe de trabalho e todas as ações educativas realizadas na edição 2018. Cada encontro teve uma duração média de 02 horas.

A reunião de alinhamento foi fundamental para conhecer melhor a equipe de trabalho e apresentar as informações gerais sobre o Projeto, bem como esclarecer sobre a dinâmica da prática educativa, dividida em três fases abordagem inicial com os acampados, acompanhamento/avaliação das ações propostas, e cerimônia de premiação aos piquetes que se destacaram pela adoção de práticas sustentáveis. Além disso, foi discutido sobre o atendimento do Projeto à PNRS, instituída pela Lei 12.305 de 2010, e sua contribuição para os Objetivos de Desenvolvimento Sustentável promovidos pela ONU, em especial o ODS 12.

No primeiro encontro também foi salientado a importância da atuação dos agentes de Educação Ambiental junto aos acampados, seu papel de mediador do processo educativo e sua contribuição para transformar a realidade do evento, intervindo para sensibilizar os acampados a mudar os seus hábitos, realizar a prática de coleta seletiva e o encaminhamento dos

revista brasileira educação ambiental 
resíduos à reciclagem, de modo a alcançar o objetivo do Projeto. Jacobi (2003) fala da possibilidade de motivar e sensibilizar as pessoas através da Educação Ambiental e Freire (1996) destaca que a educação deve possibilitar a transformação social, sendo essa a função dos agentes de Educação Ambiental do Projeto.

Já no encontro de treinamento, as informações foram bem mais aprofundadas que no primeiro encontro, pois o objetivo principal era preparar os participantes para a prática educativa em campo, capacitando-os quanto à adequada forma de abordagem e a postura frente ao público-alvo. A prática de Educação Ambiental foi trabalhada a partir da discussão de três conceitos sensibilização, informação e mobilização -, pois eles são fundamentais para o processo de construção de conhecimentos da temática ambiental e foram baseados nos objetivos de Educação Ambiental propostos pela Conferência de Tbilisi.

A ação de sensibilizar se constitui como uma prática de trazer o acampado/aluno para junto da temática de estudo, tornando-o, neste caso, sensível a necessidade de praticar a separação de resíduos, através da coleta seletiva, compreendendo sua importância para a sustentabilidade do ambiente e do evento do Acampamento. Para que o público-alvo se sensibilize com o que está sendo proposto é também essencial que o educador crie um vínculo com o acampado, chamando-o pelo nome e estando atento ao contexto que ele está inserido, de forma empática. $\mathrm{Na}$ tentativa de aproximar educador e acampado foi ainda recomendado que os participantes utilizassem adereços da vestimenta gaúcha, como o lenço e a bombacha (calça larga que compõe a indumentária do gaúcho), caracterizando-se com o ambiente de atuação.

Nessa situação, foi ressaltado para os educadores que os acampados estão em um evento cultural, uma atividade de celebração das tradições gaúchas, dentro de seu piquete (casa), festejando com seus amigos e familiares, sendo o agente de Educação Ambiental uma pessoa 'estranha', que precisa cativar o acampado/aluno e envolvê-lo para junto do objetivo do Projeto. Gohn (2006) aborda que a participação dos indivíduos em uma atividade não-formal é geralmente optativa, dado que acontece em situações construídas coletivamente, via compartilhamento de experiências em ações cotidianas, cabendo, assim, ao educador a habilidade de envolvê-lo.

O acampado/aluno, uma vez sensibilizado, mostrando-se interessado a fazer parte do objetivo proposto, precisa estar bem informado, assim como o educador. Desse modo, o treinamento contou com a apresentação e explicação de um cartaz informativo e de adesivos de lixeira, denominados como "reciclável" e "orgânico/rejeito", que seriam utilizados na ação de Educação Ambiental com os acampados, para que se pudesse também tirar dúvidas dos educadores, e sobre a entrega de um folheto com dicas sustentáveis, disponibilizado na fase de inscrição do evento.

Além disso, foi repassado que a linguagem do educador deveria ser bem clara e objetiva, e com respeito aos conhecimentos de origem dos 
acampados, pois no evento participam pessoas de todas as regiões do RS, sendo um público bem diverso, que poderia não estar familiarizado com as nomenclaturas da prática de coleta seletiva. Para Freire (1996), o ato de ensinar exige do educador o respeito pelos saberes do educando, os quais são socialmente construídos na vida em comunidade, devendo o educador estar sensível a essa questão.

Outra ação educativa discutida no encontro foi a respeito da importância do educador de mobilizar o acampado, incentivando-o a participar da coleta seletiva e demonstrando o impacto de uma ação individual para o bem coletivo. Para garantir a participação das pessoas e a continuidade de projetos, é preciso fazer uso de princípios e metodologias de sensibilização e mobilização, pois não basta informar para que haja participação (IPEA, 2012). Sendo assim, os agentes de Educação Ambiental foram orientados a provocar o acampado e contagiá-lo, questionando também se o Projeto poderia contar com a sua participação.

Os dois encontros se propuseram a dar todas as informações necessárias à prática educativa no Acampamento, com base na experiência de edições anteriores e características do local de atuação, e no atendimento a documentos legais, a exemplo dos objetivos de Educação Ambiental propostos na Conferência de Tbilisi. Embora tenham sido repassadas algumas orientações e recomendações ao grupo de trabalho, vale destacar que a prática educativa é dinâmica, cabendo ao educador, no desenvolvimento de sua prática, pensar nas melhores estratégias para atingir seus diferentes alunos, estando também atento aos conhecimentos já construídos.

Como resultado, dos 14 participantes selecionados no edital, apenas 10 atuaram nas atividades do Projeto, devido ao não comparecimento nos encontros (reunião de alinhamento e treinamento), impossibilidades de horários para participar do evento ou desistência por motivos pessoais. O grupo formado foi dividido em duplas, sendo que 4 duplas foram designadas a atuar diretamente com os acampados, dentro dos piquetes, e uma dupla com os visitantes do evento, que se concentravam na Praça das Churrasqueiras, não sendo o foco desse estudo.

\section{Desenvolvimento de estudos, pesquisas e experimentações}

No decorrer das nove edições muitas adaptações foram realizadas no Projeto, como a capacitação de recursos humanos e a adequação de materiais e métodos educativos, a fim de buscar o aprimoramento constante da prática de Educação Ambiental e alcançar melhores resultados na coleta seletiva do evento. Essas adaptações foram baseadas no desenvolvimento de estudos e pesquisas, a partir de contribuições dos acampados e da equipe de trabalho e fundamentos teóricos, além de experimentações realizadas no Acampamento a cada nova edição. 
De acordo com Freire (1996), não há ensino sem pesquisa. Portanto, é importante que o educador, ao desenvolver uma atividade de Educação Ambiental não-formal, tenha um amplo conhecimento do local de atuação e de seu contexto histórico-cultural, uma vez que o espaço não-formal é dinâmico, com um público que pode ser bem diverso. O Acampamento Farroupilha, por exemplo, acontece num parque público, com uma área de 65 hectares, reunindo na edição 2018 um total de 363 piquetes em uma das maiores festas folclóricas do Brasil. Segundo dados do MTG, uma média de 800 mil pessoas circularam no Acampamento Farroupilha em 2018, com a participação de acampados vindos de todas as regiões do Estado, de entidades públicas e privadas e estabelecimentos comerciais, o que demonstra a amplitude do evento, sua diversidade de público e o potencial para desenvolver atividades educativas. De acordo com a LDB (1996), a educação também abrange os processos formativos que se desenvolvem nas manifestações culturais, sendo o Acampamento uma oportunidade para trabalhar o tema dos resíduos sólidos.

Outro ponto que merece destaque é o desenvolvimento de estudos e pesquisas para envolver pessoas e organizações que estejam direta e indiretamente vinculados ao foco do trabalho educativo, nesse caso, a temática dos resíduos sólidos. Por isso, a Coordenação do Projeto, desde a primeira edição, mantém contato com a organização do evento (MTG), que é a responsável pela gestão dos resíduos e possibilita o desenvolvimento das ações educativas com os piquetes participantes. A Coordenação do Projeto articula também o envolvimento de empresas, na condição de patrocinadores e apoiadores, com vistas a viabilizar a aquisição de materiais educativos, instrumentos de apoio e a estrutura necessária ao desenvolvimento das atividades. Envolver atores sociais que fazem parte da cadeia de produção e consumo de bens e serviços é essencial para promover a responsabilidade compartilhada, a Educação Ambiental dos colaboradores e a adequada gestão de resíduos, ainda mais quando um evento gera uma enorme quantidade de resíduos, como o Acampamento Farroupilha.

Ademais, percebeu-se, ao longo das edições do Projeto, a necessidade de acompanhar o processo de coleta seletiva e garantir seu pleno funcionamento. As experiências em campo revelaram que não basta educar os acampados para fazer a separação de resíduos se o processo de recolhimento dos materiais possui falhas, não sendo bem executado na prática. $O$ educador deve atentar para todo processo a que seu objeto de estudo está inserido, de tal maneira que a ação educativa precisa estar vinculada a atividade prática, para que o trabalho também faça sentido ao aluno. Para tanto, na edição 2018, foi articulada a parceria da Coopertuca, uma Cooperativa de Catadores de Materiais Recicláveis de Porto Alegre, que foi responsável por fazer a coleta dos recicláveis durante todo o evento, tendo o acompanhamento constante da Coordenação do Projeto. Após a coleta, o material foi encaminhado a Unidade de Triagem (UT) da Cooperativa, sendo depois direcionado às indústrias de reciclagem. Os resíduos orgânicos/rejeitos ficaram sob a responsabilidade de 
uma empresa contratada pela Direção do MTG, não tendo envolvimento com o Projeto.

Uma vez conhecida a dimensão do objeto de estudo, a partir de pesquisas das características do local e do público-alvo e estabelecido o envolvimento de atores sociais, é necessário difundir essas informações com o grupo de trabalho, visto que toda equipe deve estar ciente do ambiente de atuação da prática educativa. No caso do Projeto, essas informações foram todas discutidas durante os encontros de alinhamento e capacitação dos agentes de Educação Ambiental e atualizadas no decorrer da execução do Projeto a cada novo acontecimento.

\section{Produção e divulgação de material educativo}

Estando os educadores cientes das atividades de campo e providos de informações sobre o público-alvo, torna-se relevante investir na produção e divulgação de materiais educativos, utilizados para orientar educador e aluno, informando sobre o objeto de estudo e servindo de referência para a ação prática. Os meios de acesso a informação são essenciais para que as pessoas participem corretamente das atividades, sem contar que qualquer dificuldade de entendimento ou de clareza das informações pode resultar no desânimo de um participante, diminuindo o seu envolvimento nas atividades (IPEA, 2012).

No Projeto, foram utilizados como materiais educativos um cartaz informativo, entregue para cada acampado e fixado dentro dos piquetes, e adesivos de lixeira, colados em cada uma das lixeiras dos acampados. Os adesivos de lixeira foram divididos em "reciclável" e "orgânico/rejeito", assim definidos por estarem de acordo com a PNRS e possuírem a mesma nomenclatura utilizada pelo Município de Porto Alegre, local de realização do evento. Os adesivos tinham cores distintas, verde para o "reciclável" e marrom para o "orgânico/rejeito", a fim de facilitar a identificação visual, e traziam exemplos de materiais que deveriam ser colocados em cada lixeira, auxiliando o acampado na correta separação dos resíduos. A Figura 1 (próxima página) mostra os materiais educativos utilizados.

Os resíduos gerados foram oriundos de atividades cotidianas, similares ao da coleta doméstica, já que os acampados utilizam os piquetes como casa durante os 20 dias de Acampamento. É importante destacar que toda a mobília e objetos utilizados nos piquetes são de responsabilidade dos acampados, cabendo a eles providenciar as suas próprias lixeiras. No entanto, alguns piquetes acabaram não trazendo mais de uma lixeira para o evento, utilizando como alternativa para acondicionar os resíduos e de iniciativa do Projeto o uso de sacos de lixo pregados nas paredes. Apesar de o Projeto existir há nove edições e a maioria dos acampados terem ciência da prática de coleta seletiva, a preocupação em trazer duas lixeiras para o Acampamento nem sempre é uma prioridade, sem contar que os acampados não são sempre os mesmos e, a cada ano, cerca de $10 \%$ dos piquetes são novos, não tendo participado da edição anterior. Além disso, não há nas cláusulas do regulamento de 
participação do Acampamento a obrigatoriedade da coleta seletiva, sendo a cada edição um desafio para a equipe de Educação Ambiental trabalhar a temática dos resíduos sólidos sem essa formalização da organização do evento.

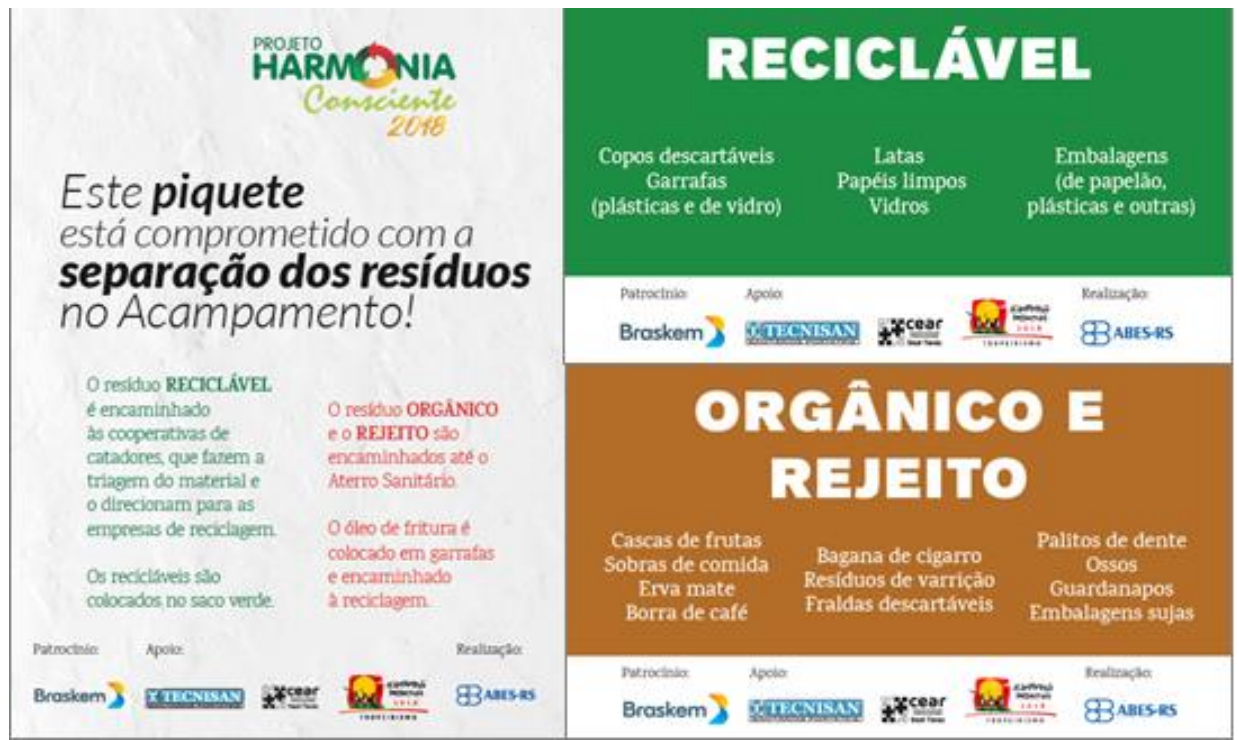

Figura 1: Cartaz informativo - à esquerda - e adesivos de lixeira - à direita Fonte: ABES/RS (2018).

Por sua vez, o cartaz informativo, alterado a cada ano, tem como objetivo divulgar o Projeto para os visitantes dos piquetes e esclarecer sobre a correta separação de resíduos e o seu destino. Na edição 2018, o cartaz teve um propósito ainda maior: o de trazer o acampado para junto da prática de coleta seletiva, tornando-o o protagonista dessa ação, através da seguinte frase: "Este piquete está comprometido com a separação dos resíduos no Acampamento!", seguida de informações sobre o caminho dos resíduos após a separação no piquete, como se fosse uma iniciativa inteiramente do acampado. Embora a mensagem tenha sido simples, ela foi pensada para envolver de fato o acampado, para que ele, uma vez se mostrando disposto a participar do Projeto, possa afirmar esse compromisso para si mesmo, de forma a se integrar àquela atitude coletiva. Dickmann e Carneiro (2012) falam dessa ideia de criar uma noção de pertencimento no mundo, para resgatar a consciência ambiental, e Freire (1996) em destacar o papel do sujeito, como aquele capaz de intervir no mundo. Nesse caso, o acampado deveria sentir-se parte do Projeto, colocando em prática a separação dos resíduos em seu piquete.

Além do conteúdo do material educativo, é importante que o educador esteja atento ao tipo de linguagem e à escrita do material (fonte e tamanho da letra), para que a mensagem seja acessível a qualquer público e as diferentes faixas etárias, não utilizando letra cursiva, por exemplo, que não são conhecidas por algumas crianças. Do mesmo modo, é importante que o material educativo não seja apenas entregue ao público-alvo, como uma panfletagem, sem ter qualquer esclarecimento ou explicação do contexto da 
atividade. A prática educativa requer um diálogo entre educador e aluno e, por essa razão, os agentes de Educação Ambiental foram orientados a explicar a importância da coleta seletiva e da logística de separação de resíduos utilizando o cartaz informativo e os adesivos de lixeira como instrumentos de apoio, aproveitando para sanar dúvidas dos acampados e interagindo com eles. Para que os materiais educativos façam sentido ao aluno eles precisam ser bem explorados, não sendo distribuídos sem qualquer controle.

É necessário que o aluno esteja também aberto a ouvir o educador. Vale lembrar que ensinar e aprender são processos indissociáveis, na qual há uma troca entre educador e aluno. A educação não-formal depende da disposição dos indivíduos e o educando pode não estar disposto a interagir em qualquer ambiente. $O$ educador, nesse caso, precisa compreender essa situação e perceber que algumas pessoas podem não estar receptivas a desenvolver um diálogo, não sendo então o momento de abordá-las nem de entregar um material educativo. Desse modo, os agentes de Educação Ambiental foram avisados para não abordar os acampados quando eles estivessem nas atividades de preparação das refeições, organizando festas e recebendo convidados, ou se demonstrassem desinteresse em conversar naquela ocasião.

Outra ação do Projeto foi elaborar um folheto com dicas sustentáveis, para ser disponibilizado aos acampados no ato de sua inscrição no evento, ao final do mês de julho, a ser entregue pelo MTG junto com os demais documentos. $O$ folheto teve o propósito de incentivar os acampados a adotar atitudes e práticas sustentáveis na fase anterior a abertura do Acampamento, convidando-os a construir um piquete sustentável e seguindo as dicas de: usar lâmpadas de baixo consumo e telhas transparentes, para permitir a entrada de luz natural; trazer duas lixeiras para separar os resíduos; instalar caixa de gordura na pia; usar utensílios domésticos (copos e pratos) não descartáveis; construir o piquete com madeiras de reflorestamento; entre outras ações. A montagem dos piquetes começa duas semanas antes do início das atividades culturais no Acampamento, estando os acampados devidamente instalados antes da execução do Projeto. Logo, coube aos educadores somente o reforço dessas dicas e a verificação de seu atendimento.

\section{Acompanhamento e avaliação}

Do total de piquetes inscritos na edição 2018 do evento, 341 fizeram parte do Projeto e 22 não participaram, por se encontrarem fechados durante 0 período de abordagem ou por não terem sido encontrados no mapa de localização do evento. Para atender essa quantidade de público, as 4 duplas de agentes de Educação Ambiental foram distribuídas por setores e atuaram em escalas de turno, das 9 às 17 horas. A divisão do trabalho em duplas auxiliou a prática educativa, pois foram visitados uma média de 85 piquetes por dupla, possibilitando o revezamento na abordagem com os acampados. Também foi estabelecido que a mesma dupla de trabalho realizasse a prática 
educativa com o mesmo grupo de piquetes, durante todas as fases do Projeto, permitindo a criação de um vínculo entre os educadores e os acampados.

A fase de abordagem inicial ocorreu entre os dias $1^{\circ}$ e 6 de setembro e consistiu na realização das abordagens de Educação Ambiental e da disponibilização dos materiais educativos. Como resultado das visitas periódicas em cada um dos 341 piquetes, estima-se que foram realizadas uma média de 1.023 abordagens na edição 2018. Sabendo que em cada piquete havia cerca de 3 pessoas, essa média pode ser ampliada para 3.069 pessoas que foram impactadas diretamente com as atividades do Projeto. Sem contabilizar os impactos indiretos, através da fixação dos materiais educativos nos piquetes, permitindo a divulgação das ações do Projeto para os visitantes do evento (ABES/RS, 2018).

Juntamente com os materiais educativos, a equipe forneceu sacos de lixo verde de 100L para cada piquete, para ser utilizado na lixeira dos resíduos recicláveis, permitindo a fácil identificação dos acampados e da equipe de coleta da Coopertuca, que poderia reconhecer pela cor quais eram os sacos de recicláveis. Os acampados foram orientados a utilizar na lixeira do orgânico/rejeito sacos plásticos de cor preta, sacos de supermercado ou de outras cores, com exceção da cor verde, destinada ao reciclável. Também foi estabelecido que a equipe de coleta da Coopertuca ficaria responsável por entregar novos sacos verdes de lixo na medida em que os acampados entregavam os sacos cheios de resíduos. A Figura 2 mostra as atividades realizadas de Educação Ambiental e coleta de recicláveis, respectivamente.

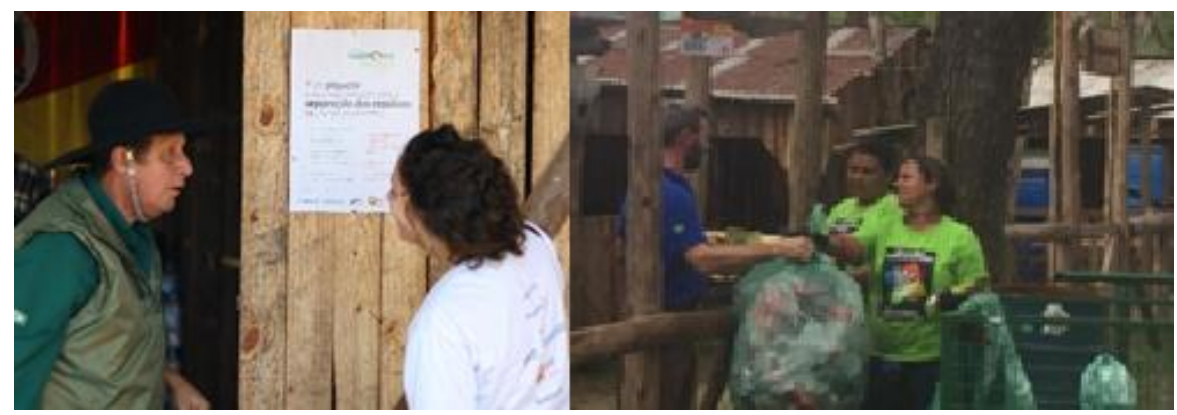

Figura 2: Prática educativa com os acampados - à esquerda -.e equipe da Coopertuca coletando os recicláveis dos acampados - à direita.

Fonte: Guilherme Goulart (2018).

A segunda fase do Projeto, de acompanhamento e avaliação das atividades educativas, ocorreu entre os dias 10 e 14 de setembro. Nessa etapa, os piquetes foram novamente visitados pelos agentes de Educação Ambiental para conversar sobre dificuldades na separação dos resíduos e verificar possíveis dúvidas ou irregularidades na coleta dos recicláveis, de modo a acompanhar todo o desenvolvimento do Projeto. Essa abordagem também serviu para avaliar os impactos da prática educativa dentro dos piquetes, a partir da utilização de uma planilha de controle, elaborada pela Coordenação do Projeto. A planilha de controle solicitava informações acerca da correta separação dos resíduos, se os recicláveis estavam visivelmente segregados; e 
se o acampado havia adotado alguma prática sustentável, sugerida no folheto de dicas sustentáveis ou recomendada na fase de abordagem, a exemplo da coleta de óleo de cozinha, ou outra de sua própria iniciativa. As informações foram registradas conforme as impressões/observações dos educadores e o depoimento dos acampados. Os dados foram contabilizados pelo número total de piquetes que aderiram à determinada prática.

Como resultado, do total de 341 piquetes, 314 foram avaliados e 27 se encontraram fechados durante o período de visita da equipe. Destes 314, foi registrado que 257 realizaram uma adequada separação dos resíduos, foco principal do Projeto, e nos demais 57 piquetes foram verificados alguns problemas na triagem dos materiais, com a presença de resíduos orgânicos/rejeitos na lixeira destinada aos recicláveis. Além do elevado percentual de piquetes praticantes da coleta seletiva (82\%), o Projeto demonstrou também uma boa abrangência, pois os dados revelaram que cerca de $48 \%$ dos piquetes multiplicaram as informações do Projeto aos seus visitantes, solicitando que eles seguissem as orientações da equipe de Educação Ambiental (ABES/RS, 2018).

Já as práticas sustentáveis demonstraram resultados pouco satisfatórios e bem esparsos. O percentual mais expressivo foi em relação ao uso de lâmpadas de baixo consumo, como as de LED, encontradas em $45 \%$ dos piquetes. Entre outros exemplos, foi verificado que $22 \%$ reutilizaram materiais recicláveis, dando-lhes uma nova utilidade, $17 \%$ coletaram óleo de fritura e apenas $7 \%$ instalaram caixa de gordura na pia (ABES/RS, 2018).

Diante dos resultados, percebe-se a necessidade de intensificar e aperfeiçoar as ações educativas para aumentar o percentual de piquetes praticantes da coleta seletiva e, sobretudo, estimular a adoção de atitudes e ações sustentáveis. Cabe destacar que a proposta avaliativa teve como foco a verificação do atendimento às práticas sugeridas/ solicitadas pela equipe, podendo ser planejado, para as futuras edições, uma análise mais abrangente e novas estratégias e metodologias para mensurar os resultados, que oportunize, por exemplo, uma avaliação dos próprios acampados em relação ao Projeto, para que eles possam discorrer sobre a abordagem e os materiais educativos utilizados. Essa foi a primeira edição que o Projeto realizou uma atividade avaliativa, e os resultados podem não ter expressado o real impacto da abordagem educativa, dado as limitações do Projeto, como em relação ao tempo dispensado para avaliar cada piquete, e as peculiaridades do evento, que possui uma alta rotatividade de visitantes nos dias de festa, prejudicando, em muitos casos, a adoção e o controle da prática de coleta seletiva, o que influencia nos resultados.

Também não se pode afirmar, com a avaliação realizada, se os acampados aderiram as práticas sustentáveis em virtude do folheto ou por iniciativa própria, sem descartar a possibilidade do folheto ter sido extraviado após a fase de inscrição. Portanto, são muitos os fatores que podem ter influenciado nos resultados, abrindo espaço para novas pesquisas e atividades 
avaliativas. O que se pretende ressaltar é a importância de realizar uma avaliação em toda e qualquer atividade de Educação Ambiental, tendo em vista a possibilidade do educador de acompanhar o estágio de desenvolvimento do seu aluno e da sua própria ação educativa, refletindo e analisando o processo por completo. Para Freire (1996), é fundamental refletir criticamente sobre a prática, em um movimento dinâmico entre o fazer e o pensar sobre o fazer, e nesse sentido, o pensar sobre a prática deve ser constante, desde a fase de planejamento até a avaliação dos resultados. A avaliação é inerente a prática de ensino e aprendizagem, devendo também fazer parte da Educação Ambiental em ambientes não-formais.

A partir da avaliação, foram escolhidos 48 piquetes para receber uma premiação, por terem se destacado na prática de separação de resíduos e encaminhamento à coleta seletiva e por terem adotado várias ações sustentáveis. O Projeto, ao longo das edições, tem presenteado alguns piquetes pela sua notória dedicação e engajamento com as ações propostas, reconhecendo-os entre os demais a partir da entrega de um certificado de "Distinção na Gestão de Resíduos Sólidos". Dos 48 piquetes, 09 receberam um reconhecimento ainda maior, pelo grande envolvimento nas atividades do Projeto, e foram convidados a comparecer numa cerimônia de premiação para receber uma cesta com produtos sustentáveis. A cerimônia aconteceu no dia 17 de setembro, no piquete da rede Record, e teve a presença de acampados, da equipe de trabalho, patrocinadores e apoiadores do Projeto. Na ocasião, foi transmitido um vídeo sobre o Projeto e as atividades de Educação Ambiental da edição 2018 e realizado um café colaborativo para encerrar as atividades. É preciso valorizar o trabalho daqueles que se dedicam a mudar seus hábitos e agir em prol de um ambiente mais sustentável, a exemplo da premiação aos acampados, pois essa prática também pode servir como um elemento motivador para futuras ações. Da mesma forma, é fundamental garantir com que todos os participantes saibam que contribuíram para o alcance do objetivo proposto, dando-Ihes sempre um retorno do trabalho desenvolvido.

A prática de Educação Ambiental nos piquetes demonstrou resultados positivos na gestão de resíduos do evento, contribuindo para a multiplicação de ideias sustentáveis, a sensibilização ambiental e a adesão dos acampados à coleta seletiva. De acordo com os dados da Coopertuca, $6.215 \mathrm{~kg}$ de resíduos recicláveis foram recolhidos em 18 dias de coleta. Do total coletado, $5.865 \mathrm{~kg}$ foram direcionados para as indústrias de reciclagem e $350 \mathrm{~kg}$ foram considerados rejeitos, por serem materiais que não possuem valor de venda no mercado, não sendo reciclados, ou por estarem muito sujos, com a presença de restos de comida, ossos e guardanapos (ABES/RS, 2018). O montante coletado garantiu trabalho e renda aos cooperativados e beneficiou 26 famílias, além de ter possibilitado a reciclagem dos materiais (ABES/RS, 2018).

Vale destacar que a empresa responsável pela coleta dos orgânicos/rejeitos também coletou sacos cheios de resíduos recicláveis, não informando sobre a quantidade coletada. No entanto, foi realizada uma estimativa do total de recicláveis com base no caminhão de coleta utilizado 
pela empresa contratada, essa estimativa somada à quantidade coletada pela Coopertuca resultou em cerca de $12.000 \mathrm{~kg}$ de recicláveis (ABES/RS, 2018). A expressiva quantidade de recicláveis só confirma a grande importância do Projeto para a sustentabilidade do evento e do ambiente, ao viabilizar a gestão adequada dos resíduos, a inclusão social de catadores e a Educação Ambiental de diferentes atores sociais.

O Projeto também se mostrou relevante por atender a PNRS e ter relação direta com o ODS 12 da Agenda 2030, na medida em que contribui para o alcance das metas 12.5 e 12.8, ao "reduzir substancialmente a geração de resíduos por meio da prevenção, redução, reciclagem e reuso" e "garantir que as pessoas, em todos os lugares, tenham informação relevante e conscientização para o desenvolvimento sustentável e estilos de vida em harmonia com a natureza", respectivamente (GTSC A2030, 2018, p. 56).

\section{Conclusões}

A prática de Educação Ambiental realizada no ensino não-formal, através do Projeto Harmonia Consciente 2018, caracterizou-se como uma atividade de reconhecida importância, visto que oportunizou espaços de diálogo sobre a temática ambiental, ampliou o acesso a informação e promoveu a reflexão e a responsabilização dos atores sociais quanto às suas práticas cotidianas, sendo também uma oportunidade para inspirar hábitos sustentáveis na sociedade. Seja qual for o ambiente de atuação e o público de trabalho da educação não-formal, é necessário que o educador procure compatibilizar atividades que envolvam a discussão de informações, a sensibilização e a mobilização, fornecendo todas as ferramentas para produção de conhecimentos do educando e a sua participação social.

O Projeto Harmonia Consciente 2018, pela análise e discussão dos resultados, cumpriu com seu objetivo de promover a Educação Ambiental dos participantes do Acampamento Farroupilha, a partir da realização das abordagens educativas, atingindo um elevado número de acampados e contribuindo para a adequada gestão de resíduos sólidos do evento, em relação ao montante de resíduos recicláveis coletados. O Projeto também buscou atuar em consonância com os documentos legais que versam sobre 0 tema da Educação Ambiental, dos resíduos sólidos e da sustentabilidade.

Vale destacar ainda sobre a forma como o processo educativo do Projeto foi conduzido, estando de acordo com as quatro linhas de atuação da PNEA, ao realizar a preparação da equipe de trabalho, por meio de reuniões e capacitações; pesquisar sobre o local de atuação, a fim de obter um conhecimento amplo e detalhado do contexto sociocultural do evento e das peculiaridades do público-alvo, e articular com diferentes atores sociais; atentar para a elaboração dos materiais educativos e, principalmente, acompanhar e avaliar toda a ação pedagógica. É essencial que em qualquer projeto ou atividade não-formal o educador tenha uma visão geral do processo educativo, 
não se limitando a elaboração de materiais informativos, por exemplo, mas procurando pensar em todos os detalhes que circundam a prática pedagógica e podem auxiliar na sua realização.

Sabe-se que são muitos os desafios em desenvolver um projeto ou atividade de Educação Ambiental, especialmente quando o trabalho é num ambiente informal e dinâmico, onde o público pode variar e deve ser constantemente envolvido. Todavia, sabe-se também da necessidade de, cada vez mais, se realizar ações de Educação Ambiental em todos os espaços, dado a recorrente problemática ambiental presente na sociedade atual, como a questão dos resíduos sólidos. É através de uma permanente e profunda ação educativa que se poderá alcançar a transformação social e a sustentabilidade do ambiente.

\section{Referências}

ABES/RS - Associação Brasileira de Engenharia Sanitária e Ambiental Seção RS. Relatório do Projeto Harmonia Consciente: Acampamento Farroupilha 2018.

BRASIL. Lei no 9.795, de 27 de abril de 1999. Dispõe sobre a Educação Ambiental, institui a Política Nacional de Educação Ambiental e dá outras providências. Disponível em: $<$ http://www.planalto.gov.br/ccivil 03/leis/19795.htm>. Acesso em: setembro de 2018.

BRASIL. Lei no 9.394, de 20 de dezembro de 1996. Estabelece as diretrizes e bases da educação nacional. Disponível em: $<$ http://www.planalto.gov.br/ccivil 03/leis/L9394.htm>. Acesso em: setembro de 2018.

DICKMANN, I.; CARNEIRO, S.M.M. Paulo Freire e Educação Ambiental: contribuições a partir da obra Pedagogia da Autonomia. R. Educ. Públ. Cuiabá v. 21 n. 45 , p. 87-102 jan./abr. 2012. 16 p.

FREIRE, P. Pedagogia da autonomia: saberes necessários à prática educativa. São Paulo: Paz e Terra, 1996. 165 p.

GIL, A.C. Métodos e técnicas de Pesquisa Social. - $6^{\underline{a}}$ ed. São Paulo: Atlas, 2008. 220 p.

GOHN, M.G. Educação não-formal na pedagogia social. In. 1Congr. Intern. Pedagogia Social. Mar. 2006

GTSC A2030 - Grupo de Trabalho da Sociedade Civil para a Agenda 2030. Relatório luz da Agenda 2030 de Desenvolvimento Sustentável - Síntese II. 2018. 84 p. Disponível em: <http://artigo19.org/wpcontent/blogs.dir/24/files/2018/07/Relat\%C3\%B3rio-Luz-da-Agenda-2030S\%C3\%ADntese-II.pdf>. Acesso em: setembro de 2018. 
IPEA - Instituto de Pesquisa Econômica Aplicada. Diagnóstico de Educação Ambiental em Resíduos Sólidos. Relatório de Pesquisa. Brasília, 2012. 74 p. Disponível

$<$ http://www.ipea.gov.br/agencia/images/stories/PDFs/relatoriopesquisa/121002 relatorio educacao ambiental.pdf>. Acesso em: setembro de 2018.

JACOBI, P. Educação Ambiental, cidadania e sustentabilidade. Cadernos de Pesquisa, n. 118, p. 189-205, março/ 2003.

LAKATOS, E.M.; MARCONI, M.A. Fundamentos de metodologia científica 7.ed. - São Paulo: Atlas, 2010. 320p.

PRONEA. Educação Ambiental: Por um Brasil Sustentável. Ministério do Meio Ambiente. Ministério da Educação. 4⿳亠丷a edição. Brasília, 2014. 114 p. Disponível em: $\quad<$ http://www.mma.gov.br/images/arquivo/80221/pronea 4edicao web1.pdf $>$. Acesso em: setembro de 2018.

QUADRA, G.R.; D’ÁVILA, S. Educação Não-Formal: Qual a sua importância? Revista Brasileira de Zoociências 17(2): 22-27. 2016.

UNESCO. Educação Ambiental: as grandes diretrizes da Conferência de Tbilisi. Brasília: Instituto Brasileiro do Meio Ambiente e dos Recursos Naturais Renováveis, $1997.154 p . \quad$ Disponível em: $<$ https://www.ibama.gov.br/sophia/cnia/livros/educacaoambientalasgrandesdiret rizesdaconferenciadetblisidigital.pdf>. Acesso em: dezembro de 2018.

YIN, R.K. Estudo de caso: Planejamento e métodos. Trad. Daniel Grassi - 2. ed. -Porto Alegre: Bookman, 2001. 200 p. 